\title{
ÍNDICES DE SATISFAÇÃO DE NECESSIDADE DE ÁGUA PARA O MILHO SEGUNDA SAFRA EM MATO GROSSO
}

\author{
FENNER, William - fennerwilliam@gmail.com \\ Universidade do Estado de Mato Grosso \\ DALLACORT, Rivanildo - rivanildo@unemat.br \\ Universidade Estadual de Maringá \\ MOREIRA, Patrícia Simone Palhana - patriciapalhana@gmail.com \\ Universidade do Estado de Mato Grosso \\ QUEIROZ, Tadeu Miranda de - tdmqueiroz@yahoo.com.br \\ Universidade de São Paulo \\ FERREIRA, Fernanda Da Silva - fernada.agronomiaunemat@hotmail.com \\ Universidade do Estado de Mato Grosso \\ BENTO, Thatiany Silva - thatybento@hotmail.com \\ Universidade do Estado de Mato Grosso \\ CARVALHO, Marco Antônio Camillo de - marcocarvalho@unemat.br \\ Universidade do Estado de Mato Grosso
}

\begin{abstract}
RESUMO: Objetivou-se com o presente trabalho identificar as melhores épocas de semeadura para a cultura do milho, com base na simulação de cultivos agrícolas por meio de soma térmica e índices de satisfação de necessidade hídrica, bem como determinar o balanço hídrico decendial para três municípios do Estado de Mato Grosso. Foram utilizados dados de temperatura e precipitação disponibilizados pelo INMET, em um período de 7 anos para os municípios de Cáceres, Sorriso e Tangará da Serra. A evapotranspiração potencial da cultura do milho foi calculada pelo método de Thornthwaite e Mather (1995), e o ISNA segundo Rolim, Sentelhas e Barbieri (1998). As épocas de semeadura foram determinadas de acordo com a Portaria 298/2012 do MAPA. Para as necessidades térmicas seguiu-se a proposta de Niedet al. (2005). Tangará da Serra apresentou o maior número de dias para completar o ciclo de desenvolvimento (150 dias), seguida por Sorriso (135 dias) e Cáceres $(133,8)$. Para as três regiões as épocas de semeadura I (1 de janeiro), II (15 de janeiro), III (30 de janeiro), IV (14 de fevereiro) e $\mathrm{V}$ (1 de março) são aptas ao cultivo do milho, sendo que a época VI (16 de março) se enquadra como intermediária ao cultivo.
\end{abstract}

Palavras-chave: Balanço hídrico, épocas de semeadura, Zeamays.

LEVELS SATISFACTION OF NEED OF WATER FOR SECOND CROP CORN IN MATO GROSSO

$A B S T R A C T$ : The objective of this work was to identify the best sowing time for maize based on crop simulation using the sum thermal and level of satisfaction of water requirements and determine the decendial water balance for the three municipalities of Mato Grosso state. Data of temperature and precipitation provided by INMET in a period of 7 years for the cities of Cáceres, Sorriso and Tangará da Serra. The potential evapotranspiration of maize was calculated by Thornthwaite and Mather (1995) method, and the ISNA second Rolim, Sentelhas and Barbieri (1998). The sowing dates were determined according to the Ordinance 298/2012 of the MAPA. For thermal needs was followed the proposed Nied et al. (2005). Tangará da Serra had the highest number of days to complete the development cycle (150 days), followed by Sorriso (135 days) and Cáceres (133.8). For the three regions sowing dates I (1 January), II (15 January), III (30 January 30), IV (14 February) and V (1 March) are suitable for the cultivation of corn, and the time sowing VI (March 16) is intermediary of to cultivation.

Key-words: Balance water, sowing dates, Zea mays. 


\section{INTRODUÇÃO}

São muitos os fatores que afetam o desenvolvimento e a adaptabilidade de culturas, mas os principais são a disponibilidade hídrica e a temperatura. Estes interferem nos processos fisiológicos dos vegetais e afetam diretamente a sua produtividade e sua relação com patógenos e pragas. Variações destes fatores tem influência direta na duração do ciclo das culturas e no desenvolvimento de seus subperíodos e, conhece-los é um importante passo para o alcance de maiores produtividades. Segundo Marini et al., (2012), as irregularidades na distribuição da precipitação aumentam o risco para cultivos, sendo importante a determinação de épocas de semeadura mais favoráveis ao cultivo.

Uma metodologia bastante válida na determinação das fases fenológicas das culturas é a soma térmica (soma dos graus-dia acumulados), que consiste na soma das unidades térmicas acima da temperatura base da cultura, que utilizada em conjunto com épocas de semeadura, determina-se as melhores épocas de cultivo (GADIOLI, 2000). Segundo Wagner et al. (2011), a utilização da soma térmica é pratica indicada para estimativas de duração de ciclo e fases fenológica do milho. Os autores encontraram variação de 114 e 122 dias para a duração do ciclo da cultura do milho em Guarapuava, Estado do Paraná com a utilização desta metodologia.

Maluf et al (2000), relatam que as exigências térmicas da cultura do milho variam de acordo com os genótipos, entretanto, poucas tem a capacidade de se desenvolverem abaixo de $10^{\circ} \mathrm{C}$. Farinelli et al. (2003), observaram menor desenvolvimento de caraterísticas agronômicas na cultura do milho quando submetidas à déficits hídricos e baixas temperaturas na fase de florescimento e enchimento de grão, isto se deve ao fato da necessidade de disponibilidade hídrica (umidade), para que o pólen possa germinar, formando o tubo polínico, fecundando o óvulo, que formará o grão e também à diminuição ou paralização do desenvolvimento da cultura quando submetida a baixas temperaturas. Os autores também reportam a necessidade de semeadura em épocas de baixo risco de ocorrência de déficit hídrico nos estádios de desenvolvimento mais sensíveis da cultura (SILVA et al., 2012).

Segundo Magalhães e Durães (2006), o consumo hídrico do milho é em torno de $600 \mathrm{~mm}$, podendo ser cultivado na amplitude entre 300 e $5.000 \mathrm{~mm}$. Quando em déficit hídrico, processos fisiológicos e mecanismos são ativados para alterar a falta de água, o que resulta em alterações e redução de produção final, devido a água ser fundamental, na absorção e transporte de nutrientes e a transpiração, dependente da demanda evaporativa da atmosfera e disponibilidade hídrica. Dallacort et al. (2006), reportam a importância da simulação de cultivos e produtividade, relacionando-os com a disponibilidade hídrica e períodos de déficit hídrico (LORENÇONI et al., 2010).

Em relação ao balanço hídrico para a cultura do milho a fase mais sensível ao déficit hídrico é o florescimento, que segundo Bergamachi et al. (2006), tem impacto negativo mais acentuado sobre a produção de grãos. Auxiliando o balanço hídrico tem-se o Índice de Satisfação de Necessidade de Água, variando de 0 a 1, indicando períodos de suprimento ou não da água demandada pela cultura, estes, tem sido muito utilizados em trabalhos de zoneamento de risco e determinação de épocas de semeadura (FARIAS et al., 2001).

Diante do exposto, a presente pesquisa tem por objetivo, identificar as melhores épocas de semeadura da cultura do milho, com base na simulação de cultivos 
agrícolas por meio de soma térmica, balanço hídrico decendial e índices de satisfação de necessidade hídrica para três municípios do Estado de Mato Grosso.

\section{MATERIAL E MÉTODOS}

A presente pesquisa foi realizada no laboratório de Agrometeorologia e Climatologia Agrícola, o qual é vinculado ao Centro de Pesquisas, Estudos e Desenvolvimento Agroambientais - CPEDA da Universidade do Estado de Mato Grosso - UNEMAT, campus de Tangará da Serra, localizado nas seguintes coordenadas geográficas: Latitude de 14039' Sul, Longitude de 57025' Oeste com elevação de 321,5 metros ao nível do mar.

Utilizou-se de dados decendiais de precipitação e temperatura média, os quais foram disponibilizados pelo INMET - Instituto Nacional de Meteorologia, em um período compreendido entre os anos de 2004 a 2010, para três municípios do Estado do Mato Grosso (Cáceres, Sorriso e Tangará da Serra), sendo o primeiro caracterizado pelo bioma Pantanal, o segundo bioma Amazônico e o último uma área de transição entre Amazônia-Cerrado-Pantanal. A localização e coordenadas dos mesmos encontra-se na Tabela 1.

\begin{tabular}{cccc}
$\begin{array}{l}\text { Tabela 1. Localização geográfica dos municípios } \\
\text { localizados no Estado de Mato Grosso, Brasil }\end{array}$ & Latizados para a realização do & balanço hídrico, \\
\hline \multicolumn{2}{c}{ Município } & Longitude & Altitude \\
\hline Cáceres & $16^{\circ} 04^{\prime} \mathrm{S}$ & $57^{\prime} 40^{\prime} \mathrm{W}$ & $118 \mathrm{~m}$ \\
Sorriso & $12^{\circ} 33^{\prime} \mathrm{S}$ & $55^{\circ} 43^{\prime} \mathrm{W}$ & $380 \mathrm{~m}$ \\
Tangará da Serra & $14^{\circ} 37^{\prime} \mathrm{S}$ & $57^{\prime} 28^{\prime} \mathrm{W}$ & $321,5 \mathrm{~m}$ \\
\hline
\end{tabular}

Os dados de precipitação e temperatura média decendiais foram inseridos no software CLIMA (FARIA et al., 2003), para tabulação, verificação de consistência dos mesmos e possíveis correções. Em sequência, calculou-se a evapotranspiração potencial da cultura do milho pelo método de Thornthwaite e Mather (1995), modificado por Pereira et al. (2002), o balanço hídrico decendial e o ISNA (Índice de Satisfação de Necessidade de Água) obtido pela razão entre a evapotranspiração real da cultura e a evapotranspiração potencial (ETr/ETp) segundo metodologia proposta por Rolim, Sentelhas e Barbieri (1998). No cálculo do ISNA utilizou-se os valores de Kc (coeficiente de cultura) do milho sugeridos por Souza et al. (2012), para cinco estádios de desenvolvimento, que são os seguintes: I - germinação/emergência (0.76), II - desenvolvimento vegetativo (0.82), III - florescimento (1.04), IV enchimento de grãos (1.04) e V - maturação (0.58).

Simulou-se o desenvolvimento da cultura do milho precoce para seis épocas de semeadura (1, 15 e 30 de janeiro, 14 de fevereiro, 1 e 16 de março), determinadas de acordo com a Portaria 298/2012 do Ministério da Agricultura, Pecuária e Abastecimento - MAPA, que define o zoneamento do milho $2^{a}$ safra para o Estado de Mato Grosso. As necessidades térmicas da cultura para completar os estádios de desenvolvimento foram 74,1, 342,8, 514,2, 293 e 835 graus para as fases I, II, III, IV e $\mathrm{V}$, respectivamente (NIED et al., 2005). 
Por fim, os valores de ISNA que indicam a quantidade de água consumida e a demandada para a produção máxima, foram comparados para a fase de desenvolvimento da cultura que é mais prejudicada pelo déficit hídrico, floração/enchimento de grãos, para as seis épocas de semeadura nos 7 anos avaliados para os três locais. Segundo Farias et al. (2001), são consideradas regiões favoráveis (de menor risco), aquelas que apresentam valores de ISNA iguais ou superiores a 0,65, intermediária (médio risco) entre 0,65 e 0,55 e desfavoráveis (alto risco), valores inferiores a 0,55.

\section{RESULTADOS E DISCUSSÃO}

Tangará da Serra apresentou o maior número de dias para completar o ciclo de desenvolvimento da cultura do milho (150 dias), seguida por Sorriso (135 dias) e Cáceres (134). Para o estádio de desenvolvimento I a variação ficou entre 5 e 6 dias, 20 e 24 dias para o estádio II, 31 a 36 dias para o estádio III, 19 a 22 dias para o estádio IV e de 55 a 63 dias para o estádio V (Tabela 2). Tangará da Serra, necessitou de mais dias em todos os estádios para o acúmulo de temperatura para completar os estádios de desenvolvimento, enquanto que, Cáceres necessitou de menor quantidade de dias para completar os mesmo estádio e Sorriso permaneceu intermediário as duas regiões.

Tabela 2. Graus dia acumulados nos estádios de desenvolvimento I (germinação/emergência), II (desenvolvimento vegetativo), III (florescimento), IV (enchimento de grãos) e V (maturação), para as épocas de semeadura I (1 janeiro), II (15 janeiro), III (30 janeiro), IV (14 fevereiro), V (1 março) e VI (16 março), nos municípios de Cáceres, Sorriso e Tangará da Serra para o período de 2004 a 2010

\begin{tabular}{|c|c|c|c|c|c|c|c|c|c|}
\hline \multirow{2}{*}{ Local } & \multirow{2}{*}{ Estádios } & \multicolumn{6}{|c|}{ Época de Semeadura } & \multirow{2}{*}{ Média } & \multirow{2}{*}{$\begin{array}{l}\text { No. } \\
\text { Dias }\end{array}$} \\
\hline & & $\mathrm{I}$ & II & III & IV & $\mathrm{V}$ & VI & & \\
\hline \multirow{5}{*}{ 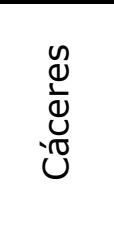 } & $\bar{I}$ & 85,5 & 86,0 & 85,5 & 86,4 & 84,9 & 80,9 & 84,8 & 5,0 \\
\hline & II & 351,4 & 350,9 & 346,9 & 348,7 & 351,0 & 352,2 & 350,2 & 20,5 \\
\hline & III & 520,2 & 523,8 & 522,9 & 519,8 & 520,3 & 518,8 & 521,0 & 31,1 \\
\hline & IV & 304,0 & 296,9 & 301,2 & 299,2 & 303,4 & 300,5 & 300,9 & 19,2 \\
\hline & $\mathrm{V}$ & 841,0 & 841,3 & 843,8 & 841,1 & 842,1 & 843,5 & 842,1 & 58,0 \\
\hline Total & & & & & & & & 2099,0 & 133,8 \\
\hline \multirow{5}{*}{ 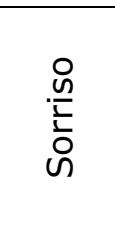 } & $\mathrm{I}$ & 80,6 & 78,8 & 80,0 & 80,0 & 84,2 & 81,6 & 80,9 & 5,3 \\
\hline & II & 350,9 & 349,8 & 346,2 & 350,2 & 349,3 & 352,7 & 349,9 & 22,4 \\
\hline & III & 525,0 & 518,8 & 521,1 & 520,5 & 521,4 & 522,3 & 521,5 & 33,1 \\
\hline & IV & 300,2 & 298,1 & 299,6 & 299,1 & 305,1 & 300,8 & 300,5 & 19,3 \\
\hline & V & 840,5 & 846,4 & 843,6 & 843,6 & 842,2 & 841,8 & 843,0 & 55,0 \\
\hline Total & & & & & & & & 2095,8 & 135,0 \\
\hline \multirow{5}{*}{ 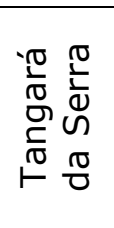 } & I & 81,1 & 80,9 & 80,2 & 81,2 & 79,9 & 81,5 & 80,8 & 6 \\
\hline & II & 349,6 & 350,9 & 349,0 & 350,2 & 345,3 & 346,8 & 348,6 & 24 \\
\hline & III & 521,8 & 521,5 & 523,9 & 525,1 & 519,7 & 519,2 & 521,9 & 36 \\
\hline & IV & 299,4 & 303,1 & 301,1 & 297,6 & 299,3 & 297,6 & 299,7 & 22 \\
\hline & V & 839,6 & 840,9 & 840,9 & 841,4 & 839,1 & 843,4 & 840,9 & 63 \\
\hline Total & & & & & & & & 2092,2 & 150 \\
\hline
\end{tabular}

Segundo Wagner et al. (2011), para estimativas de duração de ciclo de culturas as características climáticas da região em estudo devem ser o mais esclarecidas possível, para que os resultados sejam confiáveis. A diferença na duração do ciclo nas diferentes regiões pode ser atribuída a características de clima específicos de cada local. Segundo Brunini et al. (2006) o aumento da temperatura média, diminui a duração do ciclo, causado pelo aceleramento do desenvolvimento fenológico no milho. 
Pois conforme Cruz et al. (2008) a planta do milho necessita de acumular unidades de calor para poder completar cada uma das fases de desenvolvimento, que são obtidas através da soma térmica. Neste sentido cada uma das fases de desenvolvimento pode ser mais longa ou mais curta dependendo da temperatura em cada fase e de cada época de semeadura.

Isto é uma possível explicação para o observado nesta pesquisa, visto que as temperaturas médias para Cáceres, Sorriso e Tangará da Serra, foram 26,07, 25,83 e $24,60^{\circ} \mathrm{C}$, respectivamente (Figura 1 ). Como a média de temperatura de Tangará da Serra foi menor, é necessária uma maior quantidade de dias para o completo desenvolvimento de cada fase, ao contrário do município de Cáceres em que a média de temperatura foi maior durante o ciclo, necessitando o milho de um menor número de dias para completar o desenvolvimento, pois acumula um maior número de unidades de calor diário.

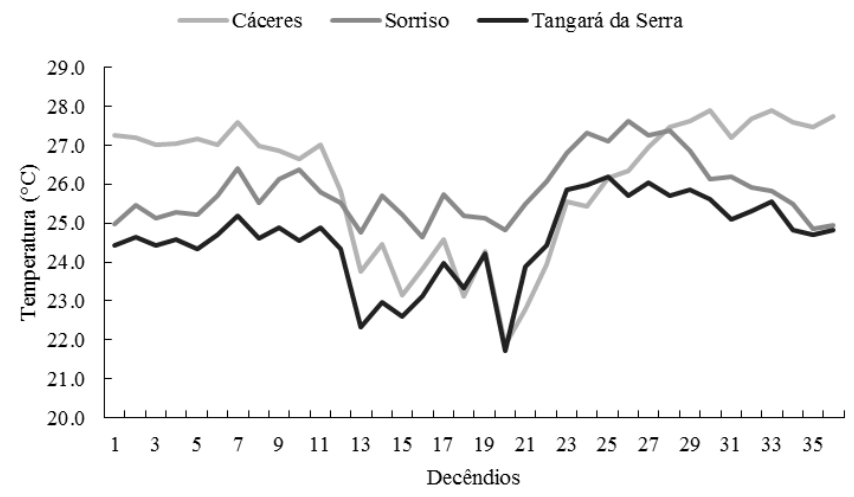

Figura 1. Temperatura média do ar decendial para Cáceres, Sorriso e Tangará da Serra, Estado de Mato Grosso (2004 a 2010)

Renato et al. (2013) avaliando diferentes métodos de soma térmica na cultura do milho e do feijoeiro verificaram a eficiência do método para simulações de cenários de aumento de temperatura. Segundo os autores, com o aumento da temperatura média do ar ocorre o encurtamento das fases reduzindo o ciclo total da cultura.

Comportamento semelhante também foi observado por Wagner et al. (2011), avaliando a soma térmica no desenvolvimento da cultura do milho, observaram um encurtamento das fases de desenvolvimento do milho em Guarapuava com o aumento da temperatura média do ar, que em consequência aumenta as unidades térmicas diárias, acelerando o desenvolvimento da cultura. O conhecimento da duração dos estádios de desenvolvimento quando relacionado aos índices de temperatura e de precipitação, são uma ferramenta de auxílio na tomada de decisão. Desta forma é possível simular o desenvolvimento para adequar a semeadura em épocas que proporcionaram menor risco de quebras no desenvolvimento da cultura.

Na figura 2 estão apresentados as médias decendiais de precipitação pluviométrica para os municípios de Cáceres, Sorriso e Tangará da Serra, Estado de Mato Grosso. 


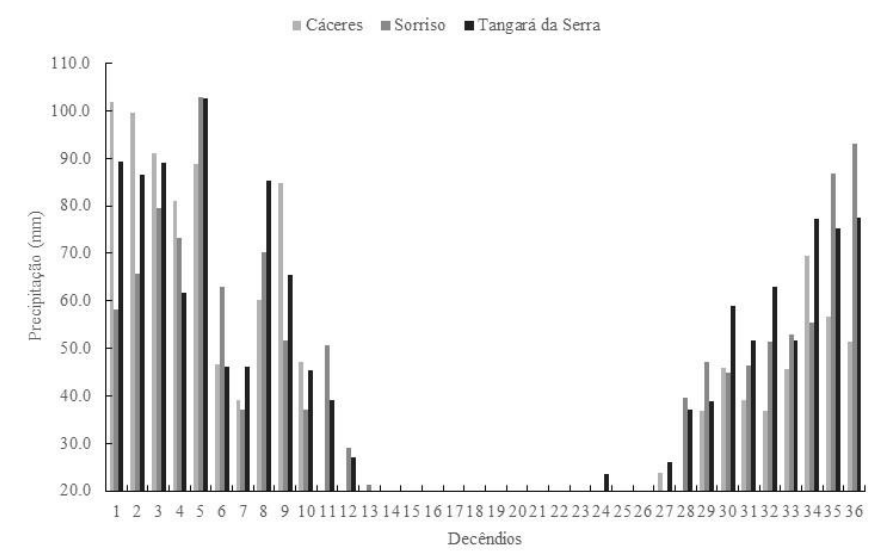

Figura 2. Precipitação média decendial para Cáceres, Sorriso e Tangará da Serra, Estado de Mato Grosso (2004 a 2010)

É observado variações no acumulado de chuva para os diferentes locais, os quais não seguem um padrão. Tal comportamento é característico das regiões, sendo comum a ocorrência curtos períodos de estiagem em plena época chuvosa. Para as três regiões, as chuvas cessam a partir do $12{ }^{\circ}$ decêndio e iniciam a partir do $26^{\circ}$ decêndio, caracterizando assim um inverno seco e verão chuvoso.

O município de Cáceres apresenta valores de evapotranspiração potencial maior que Sorriso e Tangará da Serra do decêndio 29 ao 13, seguido por Sorriso e Tangará da Serra (Figura 3). Este maiores valores de evapotranspiração, estão relacionados a demanda atmosférica e a maior disponibilidade hídrica nos municípios de Cáceres e Sorriso. Em Cáceres, localizado no Pantanal e Sorriso no bioma Amazônico. Já Tangará da Serra, por estar inserida em uma região de transição entre florestacerrado-pantanal, caracterizado pela predominância da vegetação de cerrado, tem menor disponibilidade hídrica durante o ano, apresentando menores valores de evapotranspiração.

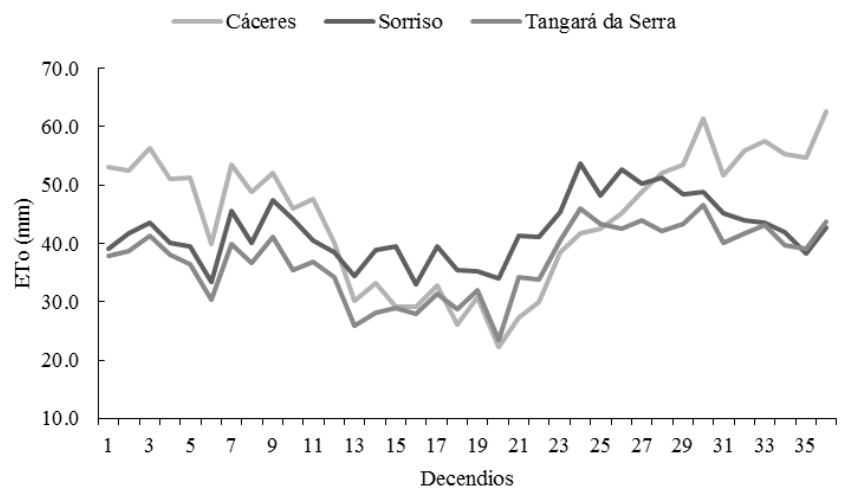

Figura 3. Evapotranspiração potencial para os municípios de Cáceres, Sorriso e Tangará da Serra, no período de 2004 a 2010

Além da disponibilidade hídrica, uma outra explicação a este comportamento da ETo é a temperatura do ar, que relacionada à disponibilidade hídrica, causa maiores ou menores valores de ETo. Para Cáceres de 26,07 e 1269,46 mm, para Sorriso 25,83 e 1538,7 e Tangará da Serra $24,60^{\circ} \mathrm{C}$ e 1418,64 mm, respectivamente.

Segundo Dallacort et al. (2010) existe correlação entre a altitude e os valores de precipitação e temperatura, no qual os valores de temperatura tendem a ser menores 
com o aumento da altitude e os de precipitação maiores. Os autores obtiveram valor de 80,4 e $84,9 \%$ para a correlação entre altitude e precipitação e temperatura, respectivamente. Esta pode ser outra possível explicação para o comportamento das regiões estudadas, sendo que Sorriso apresenta a maior altitude (380 metros), seguida de Tangará da Serra (321,5 metros) e Cáceres (118 metros).
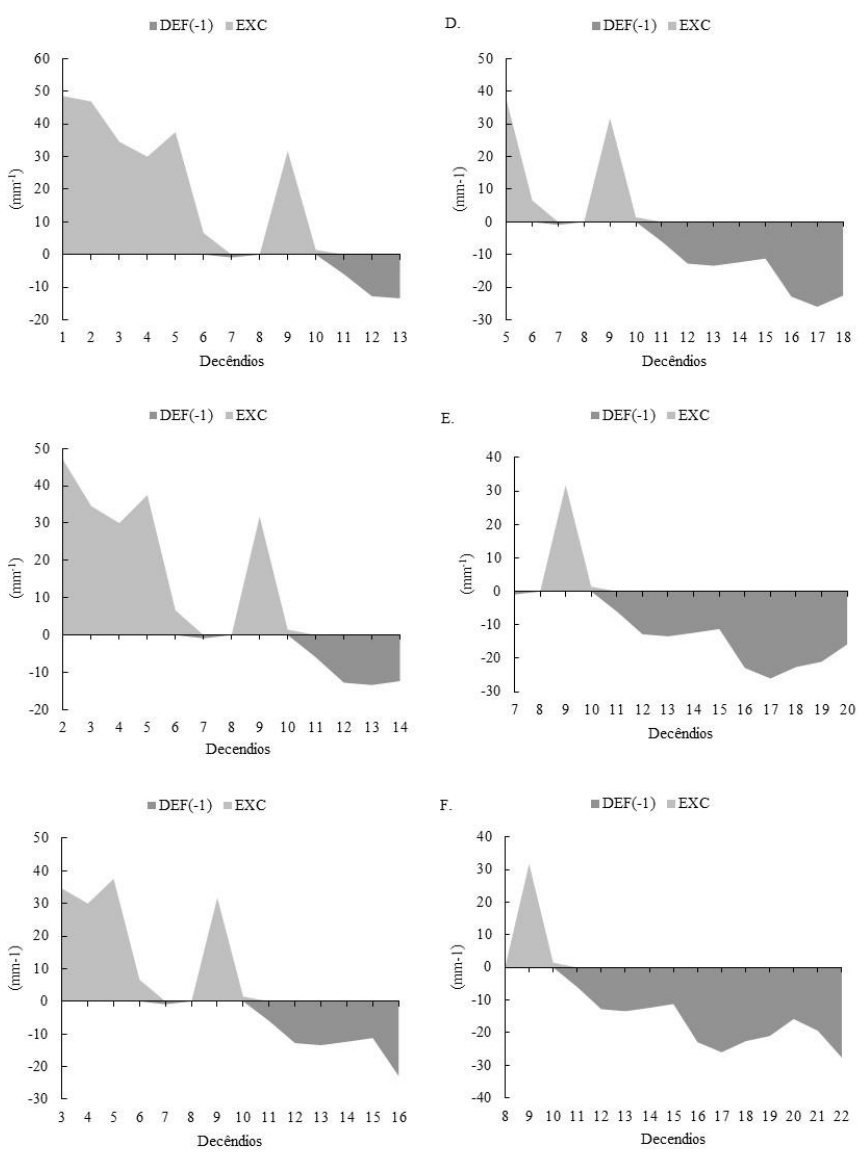

Figura 4. Balanço hídrico decendial para a cultura do milho para o município de Cáceres, conforme as diferentes épocas de semeadura: A - época I; B - época II; C - época III; D - época IV; $E$ - época V e F - época VI

Para município de Cáceres é possível verificar um comportamento bastante diferente em relação a Sorriso e Tangará da Serra (Figura 4). Para a I época de semeadura o balanço hídrico demonstrou que ocorreu excedente hídrico do $1^{\circ}$ ao $10^{\circ}$ decêndio, porém é possível perceber que no 70 decêndio ouve um pequeno déficit hídrico $(-0,9 \mathrm{~mm})$, sendo que nos últimos 3 decêndios do ciclo de desenvolvimento da planta ocorreu déficit hídrico (Figura 4A). Para a época II, em que a semeadura ocorre no segundo decêndio, verificou um comportamento semelhante ao da primeira época (Figura 4B). Para a III época foi constatado que ouve déficit hídrico nos seis últimos decêndios do período de desenvolvimento da planta (Figura 4C). NaIV época verificouse que os excedentes hídricos ocorreram apenas nos $1^{\circ}, 2^{\circ}, 5^{\circ}$ e $6^{\circ}$ decêndio após a semeadura, na maioria dos decêndios ocorreram déficits hídricos (Figura 4D). Já para as $V$ e VI épocas de semeadura (Figuras 4E e F) ocorreram excedentes hídricos apenas $3^{\circ}$ e $4^{\circ}$ decêndio após a semeadura para a $V$ época, e $2^{\circ}$ e $3^{\circ}$ para a VI época, demonstrando alto déficit hídricodurante a maioria do ciclo de desenvolvimento da cultura. 
O balanço hídrico decendial para cada época de semeadura para o município de Sorriso está apresentado na Figura 5. Na figura $5 \mathrm{~A}$ é possível verificar que para a época I de semeadura o balanço hídrico apresentou excedente hídrico na maioria dos decêndios. Já para a época II foi observado que ocorre déficit hídrico a parti do $11^{\circ}$ decêndio após a semeadura (Figura 5B). Na época III foi observado que no início do desenvolvimento da cultura ocorreu excedente hídrico, ou seja, durante os primeiros decêndios após a semeadura, e que a partir do $10^{\circ}$ decêndio ocorre deficiência hídrica (Figura $5 \mathrm{C}$ ). Nas épocas IV e $\mathrm{V}$ verificou-se que ocorreu déficit hídrico na maioria dos decêndios (Figura 5D e E). Para a época IV os excedentes hídricos ocorreram apenas nos $10,20,40$ e 70 decêndios após a semeadura, e na época $V$ foi observado excedentes apenas no $20,3^{\circ}$ e $5^{\circ}$ decêndio. Do mesmo modo para a $V$ época (figura $5 F)$ só foi observado excedente hídrico no $1^{\circ}, 2^{\circ}$ e $4^{\circ}$ decêndio.
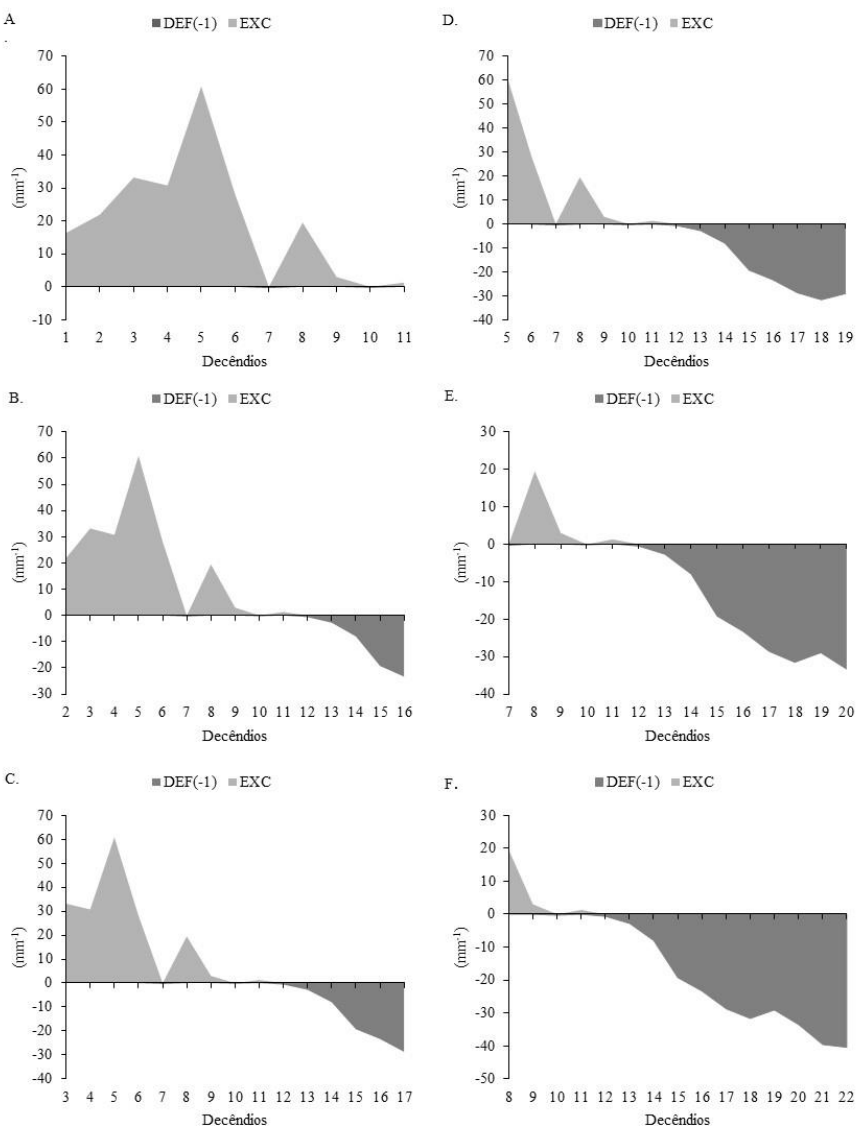

Figura 5. Balanço hídrico decendial para a cultura do milho para o município de Sorriso, conforme as diferentes épocas de semeadura: A - época I; B - época II; C - época III; D - época IV; $E$ - época V e F - época VI

Para o município de Tangará da Serra o balanço hídrico decendial esta apresentado na Figura 6, na qual é possível evidenciar que para a época I de semeadura (Figura $6 \mathrm{~A})$, ouve excedentes hídricos na maioria das fases de desenvolvimento da cultura, e que déficits hídricos ocorreram apenas a partir do $12^{\circ}$ decêndio, assim como para a segunda época (Figura 6B), em que ocorre déficit hídrico a partir do $11^{\circ}$ decêndio após a semeadura. Para o plantio que ocorre na época III verificou-se que os excedentes hídricos ocorrem até 90 decêndio após a semeadura (Figura 6C). Para as épocas IV, V e VI ocorrem déficits hídricos a partir do sétimo decêndio após a semeadura, os quais se estendem até o final do ciclo, destas destaca-se a VI época em que só ocorrem excedentes nos três primeiros decêndios após a semeadura. 

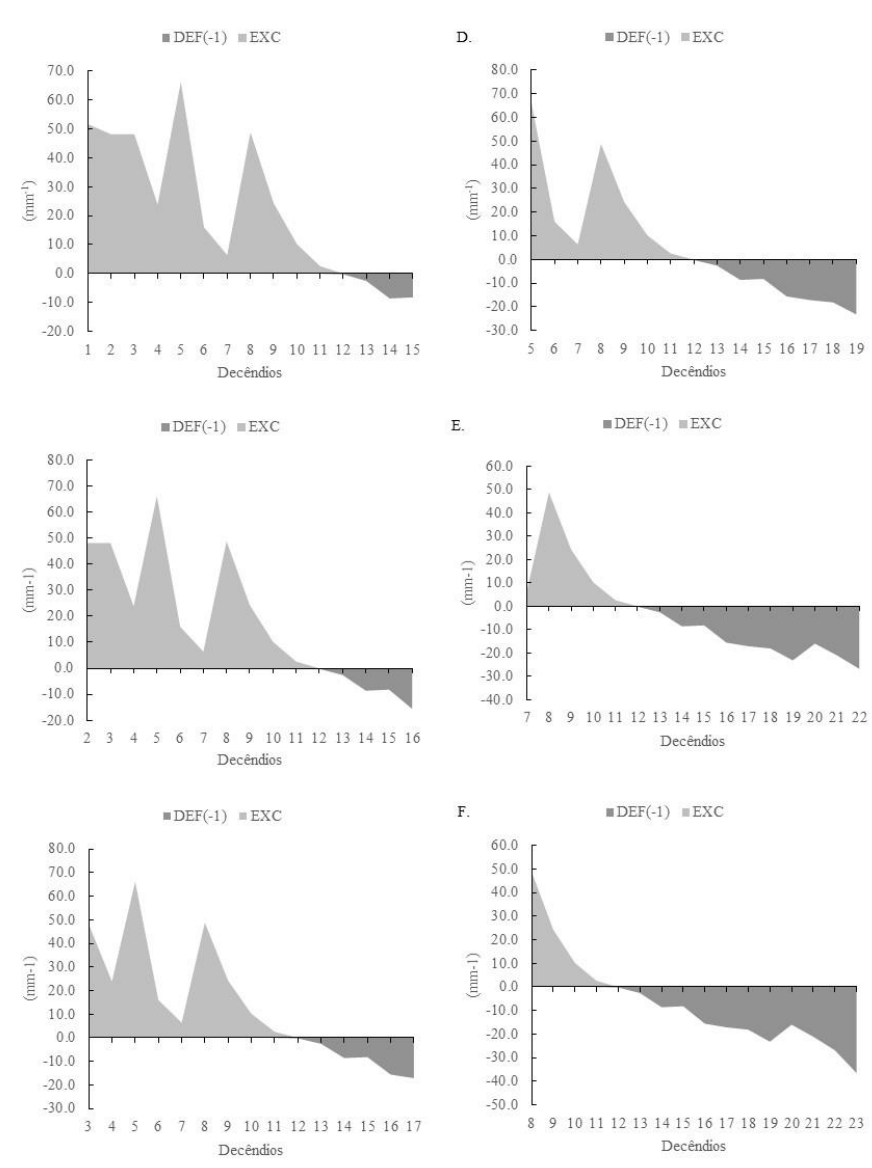

Figura 6. Balanço hídrico decendial para a cultura do milho para o município de Tangará da Serra, conforme as diferentes épocas de semeadura: A - época I; B - época II; C - época III; D - época IV; E época $V$ e $F$ - época VI

Segundo Farinelli et al. (2003), em condições de segunda safra, a cultura do milho é prejudicada por condições de ambientes desfavoráveis ao desenvolvimento, assim como as observadas neste trabalho, como exemplo os baixos índices pluviométricos a partir do $9^{\circ}$ decêndio de semeadura, comprometendo assim o sucesso do cultivo.

Segundo os mesmos autores, épocas de semeadura que coincidam com períodos de déficit hídrico na maioria dos estádios de desenvolvimento podem comprometer a produtividade final, desde que não sejam tomadas decisões para minimizar estes riscos, como exemplo da irrigação que proporciona estabilidade e maior produtividade, quando utilizada de forma racional.

Como observado nas três figuras anteriores, há períodos em que a cultura fica exposta a baixos índices pluviométricos e de umidade do solo, fazendo-se necessário o uso de técnicas e medidas que amenizem os impactos negativos do déficit hídrico para o milho. Alternativas viáveis seriam a adoção de sistema de manejo que proporcionem o maior acúmulo de matéria seca sobre o solo, como o plantio direto e culturas de cobertura na entressafra, com o objetivo de condicionar o solo e proporcionar maior umidade ao solo além de evitar variações extremas de temperatura do solo, diminuindo a evaporação. Também é louvável a adoção de sistemas racionais de irrigação, otimizando o uso da água e minimizando os impactos das variações climáticas, garantindo a produtividade. Segundo Wrege et al. (2001), também é necessário o desenvolvimento de cultivares tolerantes a períodos de 
estiagem e a seca, que aliados a época de semeadura, proporcionem menor risco de quebras de safra.

Para Nied et al. (2005), a utilização de genótipos de milho super-precocenos períodos finais de semeadura é uma alternativa ao cultivo, diminuindo o risco de coincidir a época de maior demanda por água da cultura com períodos de déficit hídrico. Desta forma, para a escolha do genótipo a ser cultivado deve ser levado em consideração o histórico do clima, previsões climáticas e épocas de semeadura baseadas em estudos de balanço hídrico e probabilidade de ocorrência de déficit hídrico.

Abaixo são apresentados os valores de ISNA para as 6 épocas de semeaduras nos municípios estudados (Tabela 3)

Tabela 3. Valores de ISNA (Índice de Satisfação de Necessidade de Água) para as seis épocas de semeadura de milho em segunda safra (época I (1 janeiro), II (15 janeiro), III (30 janeiro), IV (14 fevereiro), V (1 março) e VI (16 março), nos municípios de Cáceres, Sorriso e Tangará da Serra para o período de 2004 a 2010

\begin{tabular}{|c|c|c|c|c|c|c|c|}
\hline \multirow{2}{*}{ Local } & \multirow{2}{*}{ Ano } & \multicolumn{6}{|c|}{ Época de Semeadura } \\
\hline & & $\mathrm{I}$ & II & III & IV & $\mathrm{V}$ & VI \\
\hline \multirow{8}{*}{ 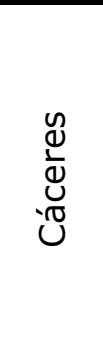 } & 2004 & 0.80 & 0.90 & 0.80 & 0.90 & 0.70 & 0.60 \\
\hline & 2005 & 1.00 & 0.90 & 1.00 & 0.70 & 0.40 & 0.40 \\
\hline & 2006 & 0.90 & 0.90 & 0.90 & 1.00 & 0.70 & 0.50 \\
\hline & 2007 & 0.90 & 0.90 & 0.90 & 0.60 & 0.30 & 0.20 \\
\hline & 2008 & 1.00 & 1.00 & 1.00 & 0.80 & 0.50 & 0.40 \\
\hline & 2009 & 0.90 & 0.90 & 0.90 & 0.90 & 0.60 & 0.70 \\
\hline & 2010 & 0.90 & 0.90 & 0.80 & 0.90 & 0.70 & 0.80 \\
\hline & Média & 0.91 & 0.91 & 0.90 & 0.83 & 0.56 & 0.51 \\
\hline \multirow{8}{*}{ 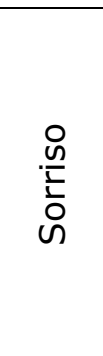 } & 2004 & 1.00 & 1.00 & 1.00 & 1.00 & 1.00 & 0.80 \\
\hline & 2005 & 0.20 & 0.10 & 0.10 & 0.00 & 0.00 & 0.00 \\
\hline & 2006 & 0.20 & 0.10 & 0.20 & 0.60 & 0.70 & 0.50 \\
\hline & 2007 & 0.90 & 0.90 & 0.90 & 0.90 & 0.90 & 0.80 \\
\hline & 2008 & 1.00 & 1.00 & 1.00 & 1.00 & 1.00 & 0.80 \\
\hline & 2009 & 1.00 & 1.00 & 1.00 & 1.00 & 1.00 & 1.00 \\
\hline & 2010 & 1.00 & 1.00 & 1.00 & 1.00 & 0.90 & 0.90 \\
\hline & Média & 0.76 & 0.73 & 0.74 & 0.79 & 0.79 & 0.69 \\
\hline \multirow{8}{*}{ 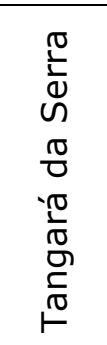 } & 2004 & 0.70 & 0.60 & 0.50 & 0.60 & 0.60 & 0.60 \\
\hline & 2005 & 1.00 & 1.00 & 0.90 & 0.80 & 0.50 & 0.50 \\
\hline & 2006 & 1.00 & 1.00 & 1.00 & 0.80 & 0.70 & 0.60 \\
\hline & 2007 & 1.00 & 1.00 & 1.00 & 1.00 & 0.80 & 0.80 \\
\hline & 2008 & 1.00 & 1.00 & 1.00 & 1.00 & 0.80 & 0.60 \\
\hline & 2009 & 1.00 & 1.00 & 1.00 & 0.90 & 0.70 & 0.50 \\
\hline & 2010 & 1.00 & 1.00 & 1.00 & 0.70 & 0.40 & 0.50 \\
\hline & Média & 0.96 & 0.94 & 0.91 & 0.83 & 0.64 & 0.59 \\
\hline
\end{tabular}

De acordo com as classes de aptidão, as épocas de semeadura mais favoráveis ao cultivo do milho para as três regiões são as épocas I, II, III, IV e V, sendo que a época VI se enquadra como intermediária ao cultivo. Percebe-se que, quanto mais tardia é a semeadura, menores são os valores de ISNA, devido a diminuição da precipitação, que passa a não suprir a demanda da cultura, tornando maior o risco de ocorrência de déficit hídrico (Tabela 3). Entre as três regiões avaliadas, Sorriso é a que apresentou os menores valores médios de ISNA, no entanto, todos dentro da faixa favorável ao cultivo (> 0.65). Segundo Sans et al. (2001) a produtividade da 
cultura do milho começa a ficar comprometida quando os valores de ISNA são abaixo de 0,40 .

Fenner et al (2014), avaliando o balanço hídrico mensal para regiões de transição entre Cerrado-Floresta-Pantanal no Estado de Mato Grosso, verificaram que o regime chuvoso é de outubro a abril para os municípios de Sorriso e Tangará da Serra e de setembro a abril em Cáceres, evidenciando a qualidade e a importância da utilização da metodologia do ISNA na determinação de melhores épocas de semeadura.

Segundo Rosa et al. (2007) e Marcuzzo et al. (2011), o comportamento das massas de ar atuante no Estado de Mato Grosso e a vegetação que o compõe (Amazônia, Cerrado e Pantanal), influenciam diretamente no regime pluviométrico e na quantidade hídrica disponível para as culturas, interferindo assim, nos valores de ISNA, uma vez que os resultados para cálculo do mesmo são dependentes do extrato do balanço hídrico.

De maneira geral, o comportamento espacial das classes de risco para o Estado de Mato Grosso, assemelha-se muito para as três CAD de armazenamento de água no solo, sendo os mesmos influenciados fortemente pelo deslocamentos das massas de ar atuantes sobre o Estado e também os biomas que o compõe (Amazônia, Cerrado e Pantanal) (ROSA et al., 2007; MARCUZZO et al., 2011).

\section{CONCLUSÕES}

A utilização da metodologia de soma térmica é adequada para a simulação das fases de desenvolvimento da cultura do milho.

Cáceres apresenta a maior demanda evaporativa nos períodos chuvosos e maior temperatura média, seguida por Sorriso e Tangará da Serra.

A duração dos estádios de desenvolvimento e ciclo total é dependente das características intrínsecas de cada local e sofre encurtamento do ciclo com o aumento da temperatura média do ar.

Para todas as regiões avaliadas, a partir do décimo decêndio (10 de abril), são registrados déficits hídricos, causados pela diminuição dos índices pluviométricos, que podem ser minimizados com a adoção de sistemas de irrigação.

De acordo com as classes de aptidão dos valores de ISNA (Índice de Satisfação de Necessidade de Água), Cáceres Sorriso e Tangará da Serra são consideradas favoráveis ao cultivo para todas as épocas (I, II, III, IV e V) exceto a VI, época em que são consideradas intermediárias ao cultivo considerando os dados e a metodologia em que o presente trabalho foi realizado.

Os estudos de épocas de semeadura e de risco climático devem ser analisados criteriosamente e atualizados constantemente, para que a informação possa ser utilizada de forma adequada. 


\section{REFERÊNCIAS BIBLIOGRÁFICAS}

BERGAMACHI, H.; DALMAGO, G. A.; COMIRAN, F.; BERGONCI, J. I.; MULLER, A. G.; FRANÇA, S.; SANTOS, A. O.; RADIN, B.; BIANCHI, C. A. M.; PEREIRA, P. G. Déficit hídrico e produtividade na cultura do milho. Pesquisa Agropecuária Brasileira, Brasília, v. 41, n. 2, p. 243-249, 2006. < http://www.scielo.br/pdf/pab/v41n2/a08v41n2.pdf >

BRUNINI, O.; ABRAMIDES, P. L. G.; BRUNINI, A. P. C.; CARVALHO, J. P. Caracterizações macroclimáticas, agrometeorológicas e restrições ambientais para o cultivo de milho em regiões tropicais baixas. InfoBibos, Campinas,v.1, n.3, 2006. <http://www.infobibos.com/Artigos/2006_3/ambientemilho/index.htm >

CRUZ, J. C.; PEREIRA FILHO, I. A.; ALVARENGA, R. C.; GONTIJO NETO, M. M.; VIANA, J. H. M.; OliveirA, M. F.; MATRANGOLO, W. J. R. Cultivo do Milho: manejo da cultura do milho. Embrapa Milho e Sorgo, Sistemas de Produção, 2, Versão Eletrônica - $4^{a}$ edição, 2008. Disponível

em: <http://sistemasdeproducao.cnptia.embrapa.br/FontesHTML/Milho/CultivodoMilho_4ed/manej omilho.htm> Acesso em 03/10/2013.

DALLACORT, R.; MARTINS, J. A.; INOUE M. H.; FREITAS, P. S. L.; KRAUSE, W. Aptidão agroclimática do pinhão manso na região de Tangará da Serra, MT. Revista Ciência Agronômica, Fortaleza, v. 41, n. 3, p. 373-379, 2010.< http://dx.doi.org/10.1590/S1806$66902010000300008>$

FARIAS, J. R. B.; ASSAD, E. D.; ALMEIDA, I. R.; EVANGELISTA, B. A.; LAZZAROTTO, C.; NEUMAIERI, N.; NEPOMUCENO, A. L. Caracterização d e risco de déficit hídrico nas regiões produtoras de soja no Brasil. Revista Brasileira de Agrometeorologia, Passo Fundo, v. 9, n. 3, (Número Especial: Zoneamento Agrícola), p. 415-421, $2001 .<$ http://trigo.cnpt.embrapa.br/pesquisa/agromet/pdf/revista/cap4.pdf>

FARINELLI, R.; PENARIOL, F. G.; BORDIN, L.; COICEV, L.; FORNASIERI FILHO, D. Desempenho agronômico de cultivares de milho nos períodos de safra e safrinha. Bragantia, Campinas, v. 62, n. 2, p. 235-241, 2003.< http://dx.doi.org/10.1590/S0006$87052003000200008>$

FENNER, W.; MOREIRA, P. S. P.; FERREIRA, F. S.; DALLACORT, R.; QUEIROZ, T. M.; BENTO, T. S. Análise do balanço hídrico mensal para regiões de transição de Cerrado-FlorestaPantanal, Estado de Mato Grosso. Acta Iguazu, v. 3, n. 1, p. 72-85, 2014. < http://erevista.unioeste.br/index.php/actaiguazu/article/view/9649>

GADIOLI, J. L.; DOURADO-NETO, D.; GARCÍA, A. G.; BASANTA, M. V. Temperatura do ar, rendimento de grãos de milho e caracterização fenológica associada à soma calórica. Scientia Agrícola, V. 57, N. 3, P. 377-383, 2000. < http://www.scielo.br/pdf/sa/v57n3/2663.pdf >

MAGALHÃES, P. C. ; DURÃES, E. O. M. Fisiologia da produção de milho. EMBRAPA (Circular Técnica 76). Sete Lagoas, 2006, 10 p.<http://www.cnpms.embrapa.br/publicacoes/publica/2006/circular/Circ_76.pdf >

MARCUZZO, F. F. N.; MELO D. C. R.; ROCHA, M. H. Distribuição espaço-temporal e sazonalidade das chuvas no Estado de Mato Grosso. Revista Brasileira de Recursos Hídricos, v.16, n. 4, p. 2011.< http://132.248.9.34/hevila/Revistabrasileiraderecursoshidricos/2011/vol16/no4/14.pdf>

NIED, A. H.; HELDWEin, A. B.; ESTEFANEL, V.; SilVA, J. C.; ALBERTO, C. M. Épocas de semeadura do milho com menor risco de ocorrência de deficiência hídrica no município de Santa Maria, RS, Brasil. Ciência Rural, Santa Maria, v. 35, n. 5, p. 995-1002, 2005. < http://dx.doi.org/10.1590/S0103-84782005000500003 > 
RENATO, N. S.; LOPES SILVA, J. B.; SEDIYAMA, G. C.; PEREIRE, E. G. Influência dos métodos para cálculo de graus-dia em condições de aumento de temperatura para as culturas de milho e feijão. Revista Brasileira de Meteorologia, v. 28, n. 4, p. 382-388, 2013.< http://dx.doi.org/10.1590/S0102-77862013000400004. >

ROSA, D. B.; SOUZA, R. R.; NASCIMENTO L. A.; TOLEDO, L. G.; TOPANOTTI, D. Q.; NASCIMENTO, J. A. A distribuição espacial das chuvas na porção Centro Oeste do Estado de Mato Grosso - Brasil. Revista Eletrônica da Associação dos Geógrafos Brasileiros. Três Lagoas - MS, v. 1, n. 5, p. 127-152, $2007 . \quad<$ http://www.matogrossobrasil.com.br/estudoscientificosmt/A\%20DISTRIBUI\%C7\%C30\%20ES PACIAL\%20DAS\%20CHUVAS\%20NA\%20POR\%C7\%C3O\%20CENTRO\%20OESTE\%20DO.pdf >

ROLIM, G. S.; SENTELHAS, P. C.; BARIERI, V. Planilhas no ambiente EXCELTM para os cálculos de balanços hídricos normal, sequencial, de cultura e de produtividade real e potencial. Revista Brasileira de Agrometeorologia, Santa Maria, v. 6, n. 1, p. 133-137, 1998.

SANS, L. M. A.; ASSAD, E. D.; GUIMARÃES, D. P.; AVELLAR, G. Zoneamento de riscos climáticos para a cultura de milho na Região Centro-Oeste do Brasil e para o Estado de Minas Gerais. Revista Brasileira de Agrometeorologia, Passo Fundo, v.9, n.3, (No Especial: Zoneamento Agrícola), p. $\quad$ p. $527-535, \quad 2001 .<$ http://trigo.cnpt.embrapa.br/pesquisa/agromet/pdf/revista/cap17.pdf >

WAGNER, M. V.; JADOSKI, S. O.; LIMA, A. S.; MAGGI, M. F.; POTT, C. A.; SUCHORONCZEK, A. Avaliação do ciclo fenológico da cultura do milho em função da soma térmica em Guarapuava, Sul do Brasil. Pesquisa Aplicada e Agrotecnologia, v. 4, n. 1, p. 135-149, 2011. < http://revistas.unicentro.br/index.php/repaa/article/viewFile/1424/1492 >

WREGE, M. S.; CARAMORI, P. H.; GONÇALVES, S. L.; COLASANTE, L. O.; FUKOSHIMA, M. T.; ABUD, N. S. Determinação das melhores épocas de semeadura do arroz de sequeiro, Oryza sativa, no Estado do Paraná. Acta Scientiarum, Maringá, v. 23, n. 5, p. 1179-1183, 2001.< http://periodicos.uem.br/ojs/index.php/ActaSciAgron/article/view/2621/2079 > 